Taking Different Paths: A Comparative Study of Mentoring Models Among Robotics Competition Teams

Mr. Nathan Dolenc, University of Virginia

1st Author Nathan Dolenc Ph.D. Student Science Education University of Virginia

2nd Author Robert H. Tai Associate Professor University of Virginia 


\title{
Taking Different Paths: A Comparative Study of Mentoring Models Among Robotics Competition Teams
}

\begin{abstract}
Mentors of high school robotics teams play important roles and influence working environments. The commonplace use of the terms mentor and mentoring in out-of-school robotics activities has opened up new areas of mentoring research. This study observed eleven robotics teams participating in the FIRST Robotics Competition investigating how the dosage of mentoring impacted student behavioral and learning outcomes. Results showed more mentor involvement led students to experience an apprenticeship structure as students learned by watching, and showed less mentor involvement led students to experience an autonomous structure as students learned by doing.
\end{abstract}

\section{Introduction}

Many have come to view robotics as a new approach to improving education and interest in the fields of science, technology, mathematics, and engineering (STEM) ${ }^{1}$. Students involved in robotics activities and competitions show an increase in attitude toward science ${ }^{2}$ and possess a greater awareness of engineering careers ${ }^{3}$. The largest high school robotics competition focused on inspiring students in STEM areas is the FIRST Robotics Competition. An important part of the FIRST program is mentoring. In general, mentoring is believed to lead to high levels of success in both personal and professional endeavors ${ }^{4}$. With respect to FIRST, mentoring is given a high level of importance and is attributed with a large part to the program's success ${ }^{5}$.

This study investigates the role of mentors in eleven different robotics teams participating in the FIRST Robotics Competition (FRC), a high school robotics contest focused on inspiring students to enter STEM careers. Mentor involvement within these robotics teams are compared to establish end points, and characterized to find where the remainder mentor visions fall within this spectrum. Our research questions are: How do mentors define their roles? How do the amount of mentoring levels differ when comparing with the other robotics teams? What are the various student behaviors under these mentoring roles?

\section{Mentorship Literature Review}

The difficulty of research obtaining an overall clear definition of mentoring is due to definitions changing based on the context mentoring exists in. An effort to define mentoring has caused an overlap of definitions that do not entirely agree with one another. Mentoring can be defined as providing young adults with career-enhancing functions, such as sponsorship, coaching, facilitating exposure and visibility, and offering challenging work or protection, all of which help the younger person to establish a role in the organization, learn the ropes, and prepare for advancement ${ }^{6}$. This definition indicates mentoring only influences younger adults. Mentoring can be defined as a developmental relationship that involves organizational members of unequal status or, less frequently, peers ${ }^{7}$. This definition implies that sometimes mentoring can occur among equals. Also, mentoring can be defined as an intense long-term relationship between a senior, more experienced individual, the mentor, and a more junior, less experienced individual, 
the protégé ${ }^{8}$. This mentor definition stresses both experience level and duration of the relationship.

Youth mentoring research often targets individuals who are considered at-risk. Youth mentoring also focuses on minority groups and underrepresented individuals. It is described as a relationship in which a more experienced adult provides ongoing guidance, instruction, and encouragement aimed at developing the competence and character of the protégé ${ }^{9}$. This implies the protégé is the person of focus and the influence in the relationship between the mentor and protégé may be unilateral. Although mentoring in FRC focuses on youth and may give opportunities for those at-risk to be involved in an activity, it is not the main focus of their activity.

Mentoring in FRC encompasses youth engaged in an after school, or out-of-school time (OST), robotics competition. Those three elements of youth, OST, and competition are key factors describing this type of mentoring as those being mentored are striving to reach their goal of building a robot. The FIRST organization defines mentoring as the process by which an experienced person provides advice, support, and encouragement to a less experienced person ${ }^{10}$. Every adult on a FRC team is a mentor simply because he or she leads through guidance and example. Although there are many definitions of mentoring to use as a framework, including the definition provided by the FIRST organization, there is a paucity of mentoring research in the context of after school or OST programs, specifically youth in STEM competitions. Because of the lack of research, we investigated how specific mentors defined their own involvement in comparison to the FRC definition of mentoring. In addition, we observed how students were behaving under their mentor's defined involvement.

\section{Methods}

The initial purpose of studying these FRC teams was to explore how the 4-H organization's sponsorship of FRC teams might be impacting youth outcomes. However, the mentor research came about as an embedded study. The development of the mentor related research questions was created only after observing and interviewing two rookie FRC teams and discovering the level of mentor involvement to be of interest.

The pathway to this comparative case study involved a process of observing eleven FRC teams and interviewing sixty-seven mentors and students within this set of teams. Overall, the FRC teams fell into two categories: 4-H sponsored and non 4-H sponsored. The nine 4-H sponsored FRC teams were chosen through the use of the 4-H network of national, state, and local representatives. Non 4-H FRC teams were chosen based on proximity to the authors. Pseudonyms were used for the names of the teams, mentors, parents, and students who participated in this study.

Observations were conducted during the official six week FRC build season, over two regional competitions, and during the championship events. Observations focused on mentors' and students' behavior, actions, and comments during club meetings and at competition events. The author was allowed to move freely within the team's workspaces, sit in on meetings, and listen in on small discussions as long as the author did not get in the way of team's progress. The 
public event status of the regional and championships events further allowed the author to conduct close observations and data collection. This overall embedded approach allowed for comprehensive data collection. Interviews with mentors and student members were also conducted, recorded, and transcribed. Lead mentors from all teams were interviewed. Additional mentor interviews were conducted based upon availability. Students interviewed were selected based on captain positions and leadership of sub-teams held. Mentors and students were asked a series of open ended questions relating to, but not limited to, how they became involved in their robotics program, what their role was within the program, how their robotics team functioned, what they gained from participating in the robotics program, how the robotics program had influenced their view of STEM careers, and how they viewed success. Interviews were intended to explore further areas of interest that appeared during the interview in addition to answering the series of predetermined questions.

\section{The Teams}

The Blue Team was a community-based veteran team of eleven years located on a university campus within a small city in a central Atlantic state. A community-based team means the participating students are drawn from the surrounding area and from local schools. The Blue Team consisted of twenty-eight student members and eight mentors. Eight hours were spent observing the Blue Team during the build season and forty hours during the competition season at two regional events. An additional two hours were spent observing the Blue Team at and end of year mentor lead meeting. Five mentors and four students were interviewed from this team.

The Light Blue Team was a school-based team, but drew a couple of students from the surrounding communities. This veteran team of six years existed on a private high school campus in a rural mountain setting in a New England state. They consisted of twenty students and six mentors. Seven hours were spent observing them during the build season. Three mentor and three student interviews were conducted.

The Green Team was a school-based ten-year veteran team located in a suburb of a large city in a central Atlantic state. The team had twenty mentors and thirty-five students. Observations included three hours during their build season and twenty hours at a regional competition. The lead mentor and four students were interviewed from the Green Team.

The Light Green Team was a community based veteran team of five years located in a small town in a New England state. They had five mentors and nineteen students of which one mentor and three students were interviewed. Six hours of observation during the build season and two hours of observation at the world championship event were spent with this team.

The Yellow Team was a school-based second year team. The school was located in a rural town in a central Atlantic state. The team consisted of three mentors and fourteen students. One mentor and five students were interviewed. A total of six hours of observations was spent with this team during the build season at their school.

The Light Orange Team was a community-based rookie team. Their team was located on the outskirts of a major university campus surrounded by a rural setting in a Midwestern state. 
The Light Orange Team had two mentors and twelve student members. Both the mentors and three students were interviewed. A total of five hours of observations were conducted during the build season.

The Orange Team was a community-based rookie team located in a small town, rural setting in a Northeastern state. They had six mentors and nine students. The lead mentor and four students were interviewed. Four hours of observations were conducted during the build season.

The Dark Orange Team was a community-based rookie team located on a community college campus in a rural area in a Midwestern state. This team had eight mentors and twenty students. Three mentors and five students were interviewed. Three hours were spent observing them at the FRC kick-off event at the beginning of the build season. An additional five hours were spent observing them at their build site.

The Red-Orange Team was a school-based second year team located in a suburb of a large city in a central Atlantic state. The Red-Orange team consisted of four mentors and twelve students. Two of the mentors and four of the students were interviewed. Six hours was spent observing this team during the build season.

The Light Red Team was a community-based veteran team of seven years located in a major city in a Southern state. This team had twenty-five mentors and thirty-three students. Only the lead mentor was interviewed, conducted by phone. Two hours of observations were spent at the world championship event.

The Red Team was a school-based veteran team of seven years located in a suburb of a major metropolitan area in a central Atlantic state. The Red Team consisted of 30 student members and 15 mentors. Seven hours were spent observing the Red Team during build season and sixty hours during the competition season at two regional events and at the world championship event. Seven mentors and six students were interviewed.

\section{Organization of Data}

Data was collected and simultaneously analyzed, compared and modified in light of new observations, and interpreted to form a spectrum of mentorship visions and involvement and a mentor-student behavior model describing the two ends of the spectrum. Codes were developed from emerging findings and themes during data analysis. The themes formed six areas: levels of involvement, types of learning, views of pathway, views of success, behavioral outcomes, rookie/veteran status. Levels of involvement described the amount of decision making occurring within the mentor-student relationships. Types of learning described the methods used for students to acquire new knowledge. Views of pathway described how students interpreted their time spent preparing their robot for competition. Views of success described how students evaluated themselves and their team. Behavioral outcomes described behavioral patterns observed under the contrasting mentor visions. Finally, rookie/veteran status described the comparison of teams over time that may lead to further research. 


\section{Findings}

\section{$\underline{\text { FRC Overview }}$}

FRC challenges teams to design and build a robot in a condensed and intense six-week period to compete in a game played in an area slightly smaller than a basketball court. FRC competitive events bring together engineering, technology, and sport in an exciting spectacle where tens to hundreds of robotics teams compete in a pop-music-infused environment in front of thousands of people. Mentors and students work together over a two and a half day period competing in a minimum of ten matches. Tournament-winning teams move on to the world championships. Additional awards are given out to best overall teams, new engineering designs, best team website and best rookie, among others. The FIRST organization believes this experience increases awareness of STEM disciplines and inspires high school aged young people to enter into careers in engineering, science, and technology.

\section{4-H Influence on Research Study}

4-H sponsorship added administrative support to FRC teams. Specifically, this included recruiting new students and mentors, finding building site locations for new teams, providing opportunities for teams to showcase their work to their surrounding communities, and finding start-up funding and future grant funding. 4-H sponsorship did not provide mentorship training nor did they provide FRC engineering or technical training to any of the teams observed. One team reported having received technical training from $4-\mathrm{H}$ for a younger level FIRST robotics competition, FIRST LEGO League, at the onset of their team.

\section{Spectrum of Mentorship}

FRC mentors came from various backgrounds. Many were engineers volunteering their free time and expertise to a team. Most mentors possessed some technical education, while some mentors were science or mathematics teachers and ran an FRC team as an after school program. Regardless of their background, each mentor observed possessed a vision of how their robotics team should function. This vision included how the mentors on the teams were involved in guiding and supporting their students. The key ingredient to each mentor's vision was the dosage of involvement and decision-making mentors took part in. Two of the eleven teams were positioned at opposite ends of a mentorship involvement spectrum: the Blue and Red teams. The other nine teams and their mentors' visions were compared within this spectrum and placed accordingly. The Blue Team had a low dosage of mentoring, while the Red Team mentors were heavily involved.

\section{Blue Team}

The lead mentor believed taking a hands-off approach would lead to more student learning. Mentors played the role of a person of resource and allowed students to make most of the decisions and run the team. Mentors viewed success as students learning and understanding the engineering design and build process on the students' terms and not based on a mentor's decision. 
"It is difficult taking a hands-off approach, but the robotics activity is not about me or any other mentor. It is about the students learning the engineering process and seeing the students' product on the field. It is easy to fall into the role of telling the students what to do but I stop short of doing so...I often have to tell parents who are new to the club and the robotics experience to step back and let the students do the work." (Lead Mentor, Blue Team)

Students from the Blue Team described the robotics experience as a rewarding way of applying knowledge and seeing their own work in action on the field. Students acknowledged the robotics activity was a competition and rankings do matter, but they were more concerned about how well they progressed on the robot, if they could foresee avoidable setbacks, how much they learned, and whether or not they were having fun. Some students said some of their best seasons didn't necessarily occur when they placed high in the rankings, but rather when their team had a cohesive vision and collaborated throughout the entire season.

\section{Light Blue Team}

Mentors strove for students to grow and develop an engineering mindset. Mentors took an approach of teaching students by first having them watch or closely assist them before setting them free to continue the task on their own. Mentors' goal was to have students doing most of the decision making and work. Mentors realized the FRC activity was complex and wanted their students to push their limits but still work within their means in order to produce the best product.

"If you take somebody and you try to teach them how to do something, about the fourth iteration they start unlearning it. This is occasionally called "drill and kill." If you teach somebody how to do something by doing it with them and then you back off and let them do it and then go through a $Q / A$ [quality assurance] process with them, which is teaching another important skill, that you always check your work with yourself and another person, then they know it forever." (Lead Mentor, Light Blue Team)

"My objective every year is to not pick up a tool but let the students do the work. I fail every year because eventually someone needs help, but I take a sitting-on-hands approach." (Build Mentor, Light Blue Team)

There was little structure provided by mentors on the Light Blue Team. Mentors initiated progress with leading questions but students were quick to take over and make it their own. Students led discussions about particular issues and problems and were eager to solve them without a mentor's aid. Students only referred back to mentors when they had completed a task and were looking for another, more experienced person to check their work. Students realized mentors played a large role in FRC, but the students' actions from creating an internal student council to the day-to-day work ensured the robotics club was student focused.

\section{Green Team}

The mentors installed a reflective approach that allowed students to find their place 
amongst the team's work and subgroups. Mentors and student leaders implemented preseason and postseason interviews with every student to cover issues, desires, working relationships, and input on the year and the coming year.

"We are striving for constant improvement, not constant change." (Student, Green Team)

"The robot is the students' project. The students are my project." (Lead Mentor, Green Team)

Students had a sense of belonging because they felt their opinion had been heard. The students also felt this reflective approach allowed their team to expand into other areas of the competition to have a more complete team. The act of expanding into more roles opened up opportunities for students with different interests to be involved and maintained high retention rates. New students were paired with veteran students for student-to-student learning. Although students accomplished most of the work, mentors, sponsors, and parents were always present to make sure progress was being made and tasks were completed correctly. The lead mentor continued to stay involved by coaching behind the student robot drivers during match play at competitions, a habit most teams didn't incorporate.

\section{Light Green Team}

Mentors regarded FRC as an opportunity for their students to be recognized in their community for their work and completing the challenge set forth by the FIRST organization. As a juxtapose position to the struggling surrounding community, mentors viewed FRC as welcoming change where teamwork is being fostered, complex problems are being solved, and everyone involved can shine. Mentors implemented teamwork activities throughout the season to build these skills.

"Our first year we bumbled through a bunch of teamwork stuff, which wasn't always easy. Our [U.S.] culture overall when you come to competition is not that of gratuitous professionalism... when you think about a football team they are trying to steal each other's signs or know what plays are coming. " (Lead Mentor, Light Green Team)

"You usually root for the other team to be unsuccessful. We were confused in the beginning. We didn't know how the FIRST competitions worked. We went to a regional competition and some kid came over and wanted to ask us about our robot and we kind of looked at each other like, what? Why are you here? But then he was really nice so we answered his questions and we realized that is how it works. You are nice to people. You help other people out, and you didn't, like, kick their robot." (Student, Light Green Team)

The teamwork approach created a cohesive atmosphere where mentors and students worked on the same level sharing the workload of designing and building the robot. All team members traded roles of leading, doing, listening, and watching. Students shared ideas that were 
the thrust of initial progress, but worked side-by-side mentors to bring these ideas to fruition. Occasionally, mentors influenced the design or construction of the robot based on their expertise.

\section{Yellow Team}

A student led team was the ultimate goal of the mentors, but the mentors made the mistake in the previous year by only allowing upperclassmen to join their robotics team. In their second year, the mentors had a year of experience, but were faced with a new batch of students. Mentors were aware they were making a lot of the decisions. Their vision of the team was creating an experience for anyone who wanted to be involved and to meet realistic goals in a highly competitive environment against more experienced veteran teams.

"Last year, we had really high expectations and we didn't meet those. This year, our goals are to do better than last year and actually be able to participate in all aspects of the game...There have been teams doing this for twenty years. Realistically, we can't hang with a team like that. We don't have the resources. We don't have the budget. We don't have the experience. To go head to head with a team like that. We can't compete. So then the strategy becomes what can we do to make ourselves the most marketable." (Teacher Mentor, Yellow Team)

Mentors and students worked side-by-side with most of the teaching being done by the mentors and learning being done by the students. Students were encouraged to work without a mentor's help, and were often entrusted by mentors to complete tasks on their own. Mentors were more involved in the decision making process, when problems arose, or when more technical work needed to be completed.

\section{Light Orange Team, Orange Team, and Dark Orange Team}

These three rookie teams had similar mentorship visions and all had students trying to design and build a robot for the first time. Mentors were guiding students and making most of the decisions. Teaching occurred solely between mentors and students. The complexity and intensity of the FRC build and competition seasons led to some understanding of how mentors were heavily involved working with first time students in order to field a robot at a regional competition. More experienced individuals, in this case the mentors, completed most of the more challenging technical work.

"We begin by trying to teach an engineering process, and actually coming up with a design before you build and not just throwing something together. We try to get them into a thinking process where they come up with many ideas...I've definitely had those times where you start building and you're like oh I'll just start building and it [idea] will come to me and you end up five weeks later with nothing." (Mentor, Light Orange Team)

Students worked in structured environments completing assigned tasks and following orders set out by mentors. Mentors dictated progress and students followed suit. Mentors attempted some modeling of procedures and set long-term student goals of learning programming and construction materials, but current decisions were mostly made by mentors. 


\section{Red-Orange Team}

The administration mentors began their FRC team for the sole purpose of increasing the chances of gaining scholarships and job prospects for their students coming out of high school. The engineering and technical mentors, the adults helping to build the robot, in their second year increased their decision involvement in the robot design, construction, and game play strategies. This action stemmed from mentors originally interpreting the FRC rules as making sure students had hands-on experience. However, after seeing other robots and interpreting them as having heavy mentorship involvement, the mentors from Red-Orange Team decided to step in and play a larger role in the team's second year.

"We are not going to be ignorant of the rules. I thought the kids had to do most of the assembly, so I got every one of them to weld on that arm. If they were asked by anyone who interviewed them if they worked on the arm they would say, 'Yes.' So I tried to involve every kid on the team or some part of the build, you know. And that's what I took it to be about. And so I'm talking to some people and they were like, 'Ahh, no no no, that ain't how it is.' I didn't realize the level it was on... when you look at some of those robots, I can tell you those kids didn't build a lot of those robots. " (Build Mentor, RedOrange Team)

Mentors stuck to a process of teaching students through demonstrations allowing them to watch and learn. The more technical mentors dictated progress of robot design and construction, and students complied. Students completed minor tasks but were hesitant about beginning more challenging tasks and instead chose to stand waiting to be told what to do. Finally, students also asked for reassurance upon completing work.

\section{Light Red Team}

The Light Red Team mentors vision was to provide a platform of winning for students to step on, be inspired, and reap the benefits by being on a high profile, big budget FRC team. Mentors believed acquiring accolades and recognition would provide new opportunities in the form of scholarships and internships to their students. Mentors also believed students learned by working next to and watching experienced engineers.

"FIRST is about inspiring more than teaching them [students]. It's perfectly legal in FIRST culture for the adults to build a beautiful robot and hand it to the kids and have them drive it at a competition, because it's about inspiring kids to want to venture into STEM technologies. And while there are a lot of teams that insist that the students do everything, they're losing out on a lot of the whole reasoning behind FIRST." (Lead Mentor, Light Red Team)

Students were exposed to a variety of cutting edge technologies. Students were shown how to perform an engineering process from established, knowledgeable engineers. Mentors and parents provided many resources, and in doing so, lowered the challenge for students to accomplish. Students were inspired and encouraged to pursue a STEM career by being on a winning team. 


\section{Red Team}

The lead mentor established an atmosphere where success meant winning, and winning meant recognition and continued support from the community and major corporate sponsors. This corporate atmosphere necessitated heavy mentor involvement to ensure continued success. The role of mentor was to ensure mistakes are kept to a minimum.

"FRC is turning into a corporation versus corporation competition. We need to have more mentor involvement in decision making to offset this unfairness...having more mentors allows students to make connections with businesses and get an understanding of future jobs." (Lead Mentor, Red Team)

Students recognized being on the Red Team was about working hard in a stressful environment. Students felt pressure to win, live up to past successes, and responsibly work with expensive equipment. Also, students viewed success as winning tournament matches, accumulating awards, and making it to the world championships. Students were inspired by the overall winning tradition, and most students ended up pursuing careers in STEM fields.

\section{Mentor-Student Behavior Model}

We defined the end of the spectrum with heavy mentorship involvement as the apprentice model where mentors made most of the decisions of design, construction, and strategy in game play. We defined the other end of the spectrum with little to no mentorship involvement as the autonomous model where mentors allowed students to make the majority of the decisions. The other nine teams and their mentors' visions fell within these two opposite poles.

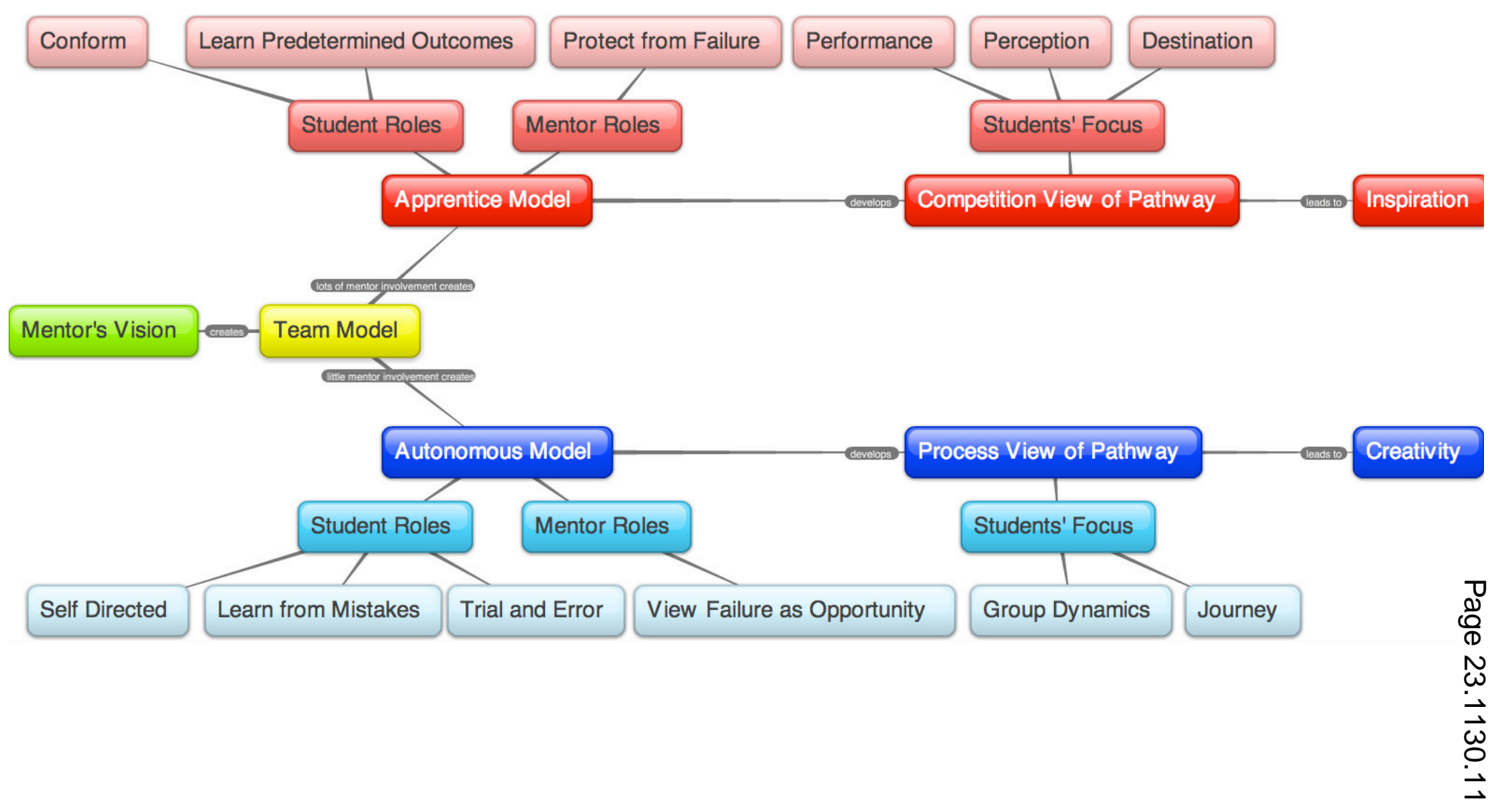


In the apprentice model, students conformed by following assignments given to them by mentors. Students learned by watching mentors' demonstrations. Mentors made most of the decisions on the robot and diminished the chance of students failing. These actions prevented students from a feeling of failure. Students took on the will to win mentality of their mentors and were concerned about their performance and perception. Students were inspired to go into STEM careers by being on a winning team.

In the autonomous model, students took control of the team. Mentors took a step back and allowed the students to learn by doing and through their own actions. Mentors saw any failure as an opportunity to learn and correct mistakes. Students did not take on the mentality of the mentors, but instead focused on positive group dynamics within their peers and having fun. Students were inspired to pursue STEM careers by being on the team regardless of their winning record.

\section{Conclusion and Discussion}

All rookie teams had heavy mentorship involvement due to the lack of student technical, design, programming, and engineering experience combined with the complexity of the robotics competition requirements. Analyzing more veteran teams, we saw some mentors' visions change to allow more student ownership of the team. In the mentor-student behavioral model, we saw two veteran teams with stark contrasting mentorship types. The mentors maintained their heavy involvement on one team whereas mentors changed their roles to allow students to run and organize on the less mentorship team. This change over years is important to understand and connect back to their rookie year by observing change over time. As teams move into more veteran status some teams may maintain heavy mentorship involvement while other teams may move away from heavy mentorship involvement. Changes in mentors' vision may provide insight into how students are behaving, how they are learning, and what they are gaining from the FRC experience.

Mentors play important roles in OST activities and need to recognize the impact they have on student development. We see varying degrees of mentor involvement between robotics teams within the FRC context. Too much mentor involvement may stunt youth development and may even turn away initially interested students from the activity. Too little involvement may set up inexperienced students for failure. The case studies presented were descriptions along this mentorship involvement spectrum. Heavy mentor involvement may expose students to the correct way to perform an engineering design process, but it strips away opportunities by not allowing students to be more engaged and learn by doing it themselves. Students in the apprentice model learn by observing, while students in the autonomous model learn by doing. Furthermore, as these groups of students continue to develop, we can suggest that those who participated in a more heavily mentor team may become dependent and mold into a team member, whereas a student who participated in a less mentorship team is more likely to become independent and develop into a team leader. 


\section{References}

1. Barker, S. B., Ansorge, J. (2007). Robotics as Means to Increase Achievement Scores in an Informal Learning Environment. Journal of Research on Technology in Education, 39(3), 229-243.

2. Welch, A. G. (2009). Using the TOSRA to Assess High School Students' Attitudes Toward Science After Competing In the FIRST Robotics Competition: An Exploratory Study. Eurasia Journal of Mathematics, Science \& Technology Education, 6(3), 187-197.

3. McGrath, E., Lowes, S., Lin, P., \& Sayres, J. (2009). Analysis of Middle-and High School Students' Learning of Science, Mathematics, and Engineering Concepts Through a LEGO Underwater Robotics Design Challenge. American Society for Engineering Education Annual Conference, Austin, TX, June 2009.

4. Merriam, S. (1983). Mentors and Protégés: A Critical Review of the Literature. Adult Education Quarterly, 33(3), 161-173.

5. 10. FIRST Mentoring Guide (2007). Retrieved from http://www.usfirst.org/roboticsprograms/frc/mentoring

6. Kram, K. E., \& Isabella, L. A. (1985). Mentoring alternatives: The role of peer relationships in career development. Academy of Management Journal, 28(1), 110-132.

7. Bozionelos, N. (2004). Mentoring provided: Relation to mentor's career success, personality, and mentoring received. Journal of Vocational Behavior, 64(1), 24-46.

8. Eby, L. T., Allen, T. D. (2002). Further investigation of protégés' negative mentoring experiences: Patterns and outcomes. Group \& Organization Management, 27(4), 456-479.

9. Rhodes, J. E. (2002). Stand By Me: The Risks and Rewards of Mentoring Today's Youth. Cambridge, Massachusettes: Harvard University Press.

Brandeis University (2005). More Than Robots: Evaluation of the FIRST Robotics Competition Participant and Institutional Impacts. Waltham, MA: Melchior, A., Cohen, F., Cutter, T., \& Leavitt, T.

National Academies (2005). Rising Above the Gathering Storm: Energizing and Employing America for a Brighter Economic Future. Washington, D.C.: National Academies Press.

Strauss, A., Corbin, J. (1998) Basics of Qualitative Research. Grounded Theory Procedures and Techniques $2^{\text {nd }}$ Ed. Newbury Park, CA: Sage. 